J. Amer. Soc. Hort. Sci. 115(4):696-699. 1990.

\title{
Surface Chemical Differences Between Sweetpotato Lines with Varying Levels of Resistance to the Sweetpotato Weevil
}

\author{
Ki-Cheol Son
}

Department of Horticulture, University of Georgia, Athens, GA 30602

Ray F. Severson and Richard F. Arrendale

Tobacco Quality and Safety Research Unit, U.S. Department of Agriculture, Agricultural Research Service, Athens, GA 30613

Stanley J. Kays

Department of Horticulture, University of Georgia, Athens, GA 30602

Additional index words. surface components, extraction methodology, biologically active compounds, silicic acid chromatography, Cylas formicarius elegantulus, Ipomoea batatas

\begin{abstract}
Methodology was developed for the extraction of surface components of sweetpotato [Ipomoea batatas (L.) Lam.] storage roots. Surface components of storage roots were quantitatively extracted with methylene chloride using 8-minute ultrasonication. After removal of the solvent, the extract was treated with 3 Tri Sil-Z :1 trimethylsilylimidazol ( $v / v)$ to convert components with hydroxyl moieties to silyl ethers and then separated on a SE-54 fused silica capillary column. Distinctly different gas chromatography profiles were found between lines displaying moderate levels of resistance ('Resisto', 'Regal', 'Jewel') to the sweetpotato weevil [Cylas formicarius elgantulus (summers)] and weevil-susceptible lines ('Centennial', SC 1149-19, W-115), indicating a possible role of surface components in insect response. Chromatographic fractionation techniques were developed for separation of major components or groups of components. The results will allow subsequent bioassaying for the presence of an ovipositional stimulant(s) and other weevil behavior-modulating compounds and their chemical characterization.
\end{abstract}

The sweetpotato weevil (Cylas spp.) is the single most economically important insect pest of the sweetpotato worldwide. It attacks both the plant in the field and the edible roots during storage. Cylas spp. feeds and reproduces almost exclusively on members of the Ipomoea genus (Cockerham et al., 1954). Some cultivars of sweetpotato have been selected that display moderate resistance to the weevil (Jones et al., 1983, 1985) and provide a potential model for studying the chemical basis for resistance. Plant breeders have often in-

Received for publication 29 Aug. 1988. We express our appreciation to $\mathrm{Al}$ Jones, USDA/ARS, Charleston Vegetable Breeding Laboratory, for the usc of his breeding lines and Max Hamilton, Clemson Univ., for providing plant material. The cost of publishing this paper was defrayed in part by the payment of page charges. Under postal regulations, this paper therefore must be hereby marked advertisement solely to indicate this fact. directly selected for increases (e.g., deterrents) or reductions (e.g., attractants, stimulants, etc.) in these biologically active compounds, using the insect as the screening tool. However, where a complex series of chemicals are modulating behavior, insect bioassays are not always sufficiently accurate to achieve useful levels of resistance. In such cases, understanding the chemistry of the compounds that modulate the interaction between insect and host is essential in that it allows for a more precise analytical approach to parent line and progeny selection (Kays and Horvat, 1983). The pragmatic use of differences in plant chemistry is now seen as a realistic strategy and has begun to have an important impact on the development of resistant lines (Hedin, 1986).

Research in our laboratory (Wilson et al., 1988) has recently shown that the surface extract from a sweetpotato cultivar susceptible to the weevil increased the oviposition frequency when 
applied to root cores of both susceptible lines and those displaying moderate levels of resistance. The following study focused on establishing the protocol for the quantitative extraction of the surface components from the storage root, which could be used for screening parent lines and progeny. In addition, we have established differences in surface chemistries between susceptible and resistant lines and have developed initial fractionation procedures for purification of selected compounds. Details on the behavior modification of $C$. formicarius elegantulus by specific surface components and the identification and chemistry of those compounds are contained in separate reports (Son et al., 1989; Wilson et al., 1989).

\section{Materials and Methods}

Materials. Three susceptible lines ['Centennial', SC1149-19), and W-115] and three lines displaying moderate levels of resistance to the sweetpotato weevil ('Jewel', 'Resisto', and 'Regal') (Mullen et al., 1981, 1985) were grown at the Univ. of Georgia Horticulture Farm during 1986 and 1987. After harvesting, the storage roots were washed, air-dried, and cured for 7 days at 29C, 90\% RH and stored at 13C, 85\% RH. Storage roots used for analysis were U.S. \#1 grade, having surface areas of 120 to $150 \mathrm{~cm}^{2}$ and no surface damage. Initial extraction and fractionation methodology was developed using the cultivar Centennial. Extractions were made using distilled-in-glass grade methylene chloride (Burdick and Jackson, Richmond, Calif.). The extracts were silylated using trimethylsilylimidazol (TMSI) and Tri Sil-Z (TMSI in dry pyridine, $1.5 \mathrm{meq} \cdot \mathrm{ml}^{-1}$ ) (Pierce Chemical, Rockford, Ill.). Hexaconsanol (Amalabs, North Haven, Conn.) was used as an internal standard (ISTD).

Extraction technique and efficiency. Five individual, cured storage roots were sequentially submerged in a beaker containing $650 \mathrm{ml}$ of methylene chloride held in an ultrasonic bath and sonicated for $2 \mathrm{~min}$. Methylene chloride was chosen because it has been shown to quantitatively extract the surface components from other species (Severson et al., 1984). After sonication, the excess methylene chloride was permitted to run into the beaker; the entire procedure was repeated seven times using additional beakers of methylene chloride. After extraction, the final volume of each beaker was brought up to $650 \mathrm{ml}$ with $\mathrm{CH}_{2} \mathrm{Cl}_{2}$ and filtered (Whatmans No. 2) through a bed of anhydrous $\mathrm{Na}_{2} \mathrm{SO}_{4}$. Each beaker and filter paper disk was washed with $30 \mathrm{ml}$ of methylene chloride, and the extract was sealed in an Erlenmeyer flask and stored in the dark at $-18 \mathrm{C}$ until analysis. The periderm of washed storage roots was then carefully dissected from the individual roots and the surface areas measured using a LICOR Model LI-3000 portable leaf area meter (LI-COR, Lincoln, Neb. ) to allow expression of components on a unit surfacearea basis.

After warming to room temperature (21C), the samples were reduced to $\approx 1 \mathrm{ml}$ using a rotoevaporator $(37 \mathrm{C}$ at $100 \mathrm{~mm} \mathrm{Hg}$ ), brought up to $5 \mathrm{ml}$ in methylene chloride, and stored ( $-18 \mathrm{C}$ in the dark) in 8-ml test tubes with Teflon-lined screw caps. After as much as 1 year of storage, no changes in level or composition of gas chromatography (GC)-detectable components were observed. The extraction procedure was repeated using three trials of five roots $\times$ seven sonications/trial.

Differences in surface chemistry between lines. Five storage roots from each line were submerged in a 4-liter beaker containing 2 liters of $\mathrm{CH}_{2} \mathrm{Cl}_{2}$ and extracted for $8 \mathrm{~min}$ in an ultrasonic bath. The surface extracts and surface area measurements were handled as previously described. The entire experiment was conducted three times.
Chromatographic separation of surface extracts. Extract (100 $\mathrm{mg}$ ) was separated by silicic acid chromatography (10 g Unisil, activity grade I, $0.5 \mathrm{~cm}$ i.d. $\times 25 \mathrm{~cm}$ glass column, $40 \mathrm{kPa}$ under $\mathrm{N}_{2}$ ) into four fractions using hexane $(100 \mathrm{ml})$, 1 methylene chloride : 3 hexane $(500 \mathrm{ml}), 1$ methylene chloride : 1 hexane $(500 \mathrm{ml})$, and 1 methanol : 19 methylene chloride (500 $\mathrm{ml})$. The fractions were reduced to $1 \mathrm{ml}$ using a rotoevaporator and stored as previously described. Recovery was $98 \%$ of the original extract weight.

Gas chromatographic analyses. In preliminary experiments, an amount of extract equivalent to $15 \mathrm{~cm}^{2}$ of surface area was found to be sufficient for GC analysis. The portion of periderm extract from each sample was transferred to a microautosampler vial, and $25 \mu \mathrm{l}$ of hexacosanol $\left(0.22 \mathrm{mg} \cdot \mathrm{ml}^{-1}\right.$ in distilled benzene), which fell in an open retention window in initial chromatograms, was added as an ISTD for quantitation in the preliminary experiments. The solvent was-removed on a nitrogen blow-down apparatus at 40C. Sixty microliters of 3 Tri Sil$\mathrm{Z}$ : 1 TMSI derivatizing reagent was added and the microautosampler vial was sealed with a crimp cap. After heating for $45 \mathrm{~min}$ at $76 \mathrm{C}$, the samples were analyzed on a Hewlett-Packard $5700 \mathrm{~A}$ gas chromatography [equipped with a 7672A autosampler and modified for GC-2 as described by Severson et al. (1984)] using a $0.3 \mathrm{~mm}$ id. $\times 30 \mathrm{~m}$ thin-film $(\approx 0.1 \mu \mathrm{m})$ SE-54 fused silica glass WCOT column [temperature program (150 to 290C at $4 \mathrm{C} / \mathrm{min}, 15 \mathrm{~min}$ hold at $290 \mathrm{C}), 54 \mathrm{~cm} \cdot \mathrm{s}^{-1} \mathrm{H}_{2}$ flow rate, 46 $\mathrm{ml} \cdot \mathrm{min}^{-1} \mathrm{H}_{2}$ split, injection port (250C), and flame ionization detector $(300 \mathrm{C})]$. Columns were prepared from Hewlett-Packard fused silica tubing according to the procedure of Arrendale et al. (1984).

\section{Results and Discussion}

Efficiency of periderm extraction. A primary concern with the extraction of plant surface components is the inadvertent extraction of internal compounds that are also solubilized. Because of this, the length of time the tissue is exposed to the solvent is a critical factor. The duration should be sufficiently long to remove the surface chemicals without the removal of internal components, the total concentration of which would accumulate with increasing extraction time. To measure extraction efficiency, we monitored the concentration (peak area) of peak 2 (boehmerol silyl ether) and peak 5 (boehmeryl acetate) (Fig. 1D), selected during initial GC separations of the surface components of the cultivar Centennial. Peak 2 was effectively removed in the first $2 \mathrm{~min}$, while peak 5 decreased over the subsequent three 2-min extractions (Table 1). We did not find an increase in the composite of any of the peaks present after four 2-min extractions or the presence of any new compounds, indicating that internal lipophilic components were not being extracted (data not presented). A similar extraction efficiency was found for the cultivar Resisto using similar peaks (data not shown).

Silicic acid chromatography. Further characterization was undertaken using silicic acid chromatography. Before column chromatography, an aliquot of the methylene chloride surface extract from 'Centennial' had the solvent removed, was resuspended in hexane, and partitioned between hexane and a methanol $(80 \%)$ /water phase. No GC-detectable components were found in the polar methanol/water fraction. As a consequence, the crude extracts were subsequently chromatographed without polar solvent partitioning.

The surface extract was separated into four fractions (hexane, 1 methylene chloride : 3 hexane, 1 methylene chloride : 1 hex- 


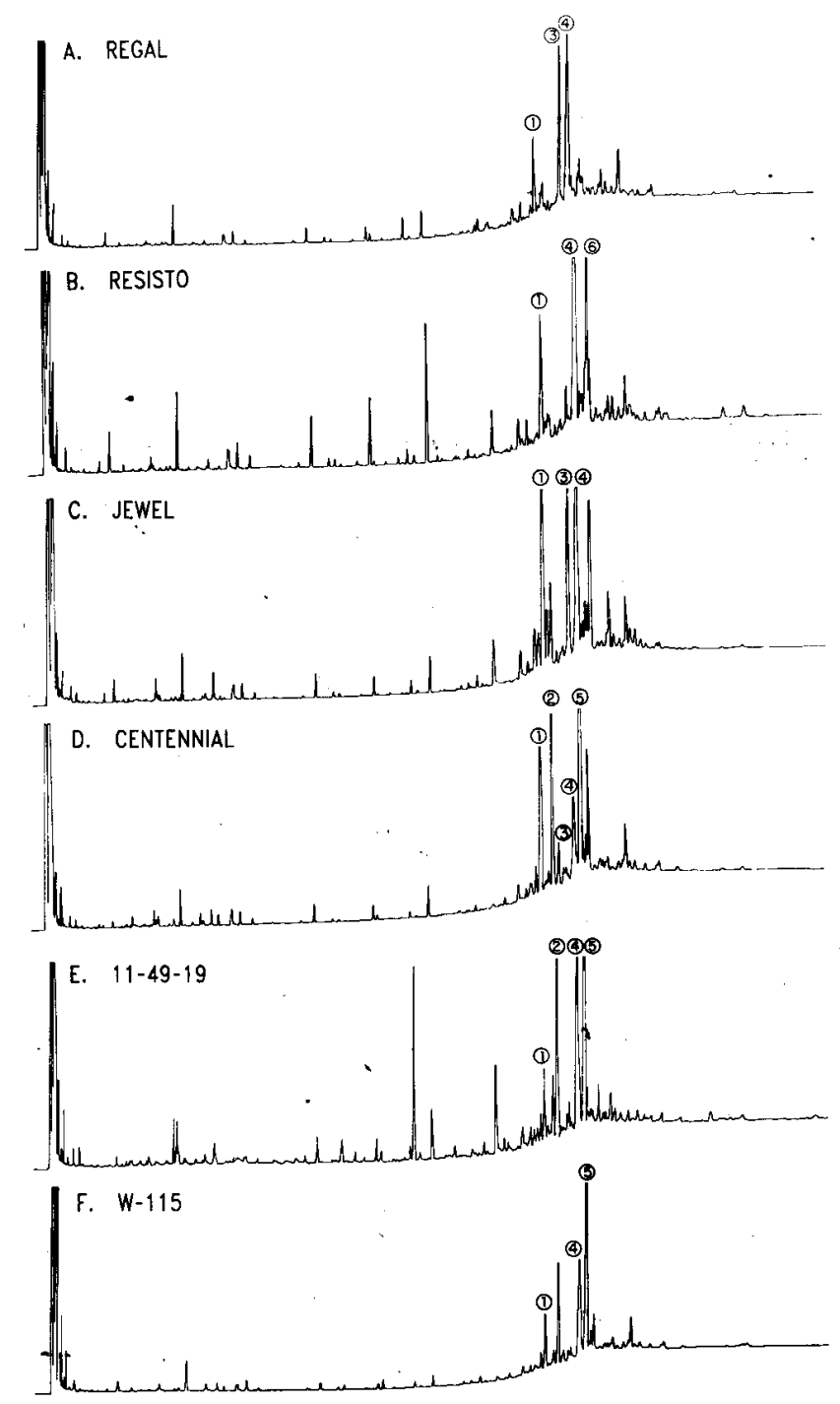

Fig. 1. Chromatograms of silylated root surface extracts of sweetpotato lines.

ane, and 1 methanol : 19 methylene chloride) by use of silicic acid chromatography. The hexane fraction, based on $\mathrm{GC} / \mathrm{mass}$ spectrometry (MS) analysis, contained only aliphatic hydrocarbons. Chain length ranged from $\mathrm{C}_{23}$ to $\mathrm{C}_{33}$. Pentacosane $\left(\mathrm{C}_{25}\right)$, heptacosane $\left(\mathrm{C}_{27}\right)$, and nonacosane $\left(\mathrm{C}_{29}\right)$ represented the primary components (K. -C.S., R.F.S., and S.J.K., unpublished data), supporting a similar finding by Espelie et al. (1980) using thin layer chromatography separation.

Of particular interest was the separation of peak 5 (Fig. ID) into the $25 \%$ methylene chloride-in-hexane fraction. This compound, subsequently identified as a pentacyclic triterpene, boehmeryl acetate (Son et al., 1989), has been shown to function as an ovipositional stimulant for the female sweetpotato weevil (Wilson et al., 1989). Thus, quantification of this component may be very useful in the selection of parent lines and progeny when breeding for weevil resistance. The 1 methylene chloride : 3 hexane fraction represented a major purification step, with boehmeryl acetate making up $\approx 96 \%$ of the GC-detectable compounds present.

The free alcohol of boehmeryl acetate (boehmerol) (Son et al., 1989) comprised peak 2 and was eluted in the $50 \%$ methylene chloride-in-hexane fraction. Components eluted with the
Table 1. Efficiency of methylene chloride in surface extraction of 'Centennial' sweetpotato roots.

\begin{tabular}{|c|c|c|c|}
\hline \multicolumn{2}{|c|}{ Extraction } & \multicolumn{2}{|c|}{$\begin{array}{c}\text { Percent of } \\
\text { total recovered }\end{array}$} \\
\hline No. & Time (min) & Peak 2 & Peak 5 \\
\hline 1 & 2 & 100 & $88.7 \pm 3.17$ \\
\hline 2 & 4 & $\ldots y$ & $6.9 \pm 1.69$ \\
\hline 3 & 6 & --- & $3.5 \pm 1.07$ \\
\hline 4 & 8 & -.. & $0.9 \pm 0.50$ \\
\hline 5 & 10 & --- & $-\cdots$ \\
\hline 6 & 12 & --- & -- \\
\hline 7 & 14 & --- & --- \\
\hline
\end{tabular}

'Two major components from the 'Centennial' crude extract were compared. Recoveries represent the average of three replications of five roots/replication.

${ }^{y}$ Absent or below detection limits.

1 methanol : 19 methylene chloride fraction were largely of high molecular weights (unpublished data).

Differences in surface chemistry between cultivars. Chromatograms of surface components from three susceptible lines and three lines displaying moderate levels of resistance were compared (Fig. 1). Identical peaks for cultivars were ascertained using GC retention time and GC/MS data. Based on the GC/MS data, molecular ions, base peaks, and fragmentation patterns, most of the high molecular weight components found were tentatively identified as triterpenoids (Table 2).

The amount of wax expressed as GC-detectable components extracted per unit of periderm surface area for the different lines ranged from 3.2 to $6.7 \mu \mathrm{g} \cdot \mathrm{cm}^{-2}$ (Table 2). This value should, however, only be considered an estimate because some surface waxes may be lost during harvest, handling, and cleaning, and some contamination of the suberin-associated waxes with waxes known to be present in soil may occur (Morrison and Bick, 1967).

In the susceptible lines, boehmeryl acetate (peak 5) represented $\approx 50 \%$ of the total GC volatile material extracted. The dominant peak in the lines displaying moderate levels of resistance was peak 4 (Fig. 1 D-F). Of considerable interest was the presence of peaks 2 and 5 in the weevil-susceptible sweetpotato lines and their absence in the resistant line. Peak 4, in contrast, which was the dominant peak in the resistant lines, was also found in each of the susceptible lines, although the concentration was significantly lower (Table 2). Therefore, distinct and consistent differences in storage root surface components were found between susceptible lines and lines displaying some resistance, indicating a possible biological role for some of these compounds in weevil response. This position was substantiated by recent work (Wilson et al., 1988) demonstrating that the methylene chloride surface extract from the storage roots of 'Centennial', one of the most susceptible lines based on laboratory (Nottingham et al., 1987) and field evaluation (Mullen, 1984), increased ovipositional frequency on surfacewashed root cores of susceptible lines and on cores from lines displaying moderate resistance (Wilson et al., 1989). Nottingham et al. (1987) reported that differences in the levels of feeding and oviposition of four sweetpotato cultivars ('Centennial', 'Jewel', 'Regal', and 'Resisto') were significant for the periderms but not evident for the inner cores of the roots, where oviposition was reduced to a very low level. Feeding, a prerequisite for oviposition, did occur on the inner cores at a reduced level compared to the root periderm in preference tests, but with little or no oviposition. The results indicated that factors re- 
Table 2. Relative concentration of storage root surface components from three weevil-susceptible sweetpotato lines and three lines displaying moderate levels of resistance.

\begin{tabular}{|c|c|c|c|c|c|c|c|}
\hline \multirow[b]{4}{*}{ Cultivar } & \multirow{4}{*}{$\begin{array}{c}\text { Weevil } \\
\text { susceptibility }\end{array}$} & \multicolumn{6}{|c|}{ Assigned peak no. } \\
\hline & & \multirow{3}{*}{$\begin{array}{c}1 \\
(1.24 / 498) \\
\end{array}$} & .2 & 3 & & 5 & 6 \\
\hline & & & \multicolumn{4}{|c|}{ (relative retention times ${ }^{\mathrm{z}} /$ molecular $\mathrm{wt}^{\mathrm{y}}$ ) } & \multirow[b]{2}{*}{$(1.34 / 426)$} \\
\hline & & & $(1.27 / 498)$ & $(1.30 / 526)$ & $(1.32 / 498)$ & $(1.33 / 468)$ & \\
\hline & & \multicolumn{6}{|c|}{$\mathrm{mg} / \mathrm{cm}^{2} \pm S E^{\mathbf{x}}$} \\
\hline Centennial & $S^{w}$ & $0.51 \pm 0.14$ & $0.66 \pm 0.04$ & $\ldots v$ & $0.27 \pm 0.01$ & $3.67 \pm 0.28$ & -.. \\
\hline W-115 & $S$ & $0.33 \pm 0.04$ & $0.54 \pm 0.05$ & $-\cdots$ & $0.65 \pm 0.15$ & $3.25 \pm 0.23$ & $\cdots$ \\
\hline $11-49-19$ & $\mathrm{~S}$ & $0.14 \pm 0.02$ & $0.54 \pm 0.05$ & --- & $0.85 \pm 0.09$ & $1.94 \pm 0.22$ & $\cdots$ \\
\hline Jewel & MR & $0.36 \pm 0.07$ & --- & $0.59 \pm 0.16$ & $1.54 \pm 0.02$ & --- & --- \\
\hline Resisto & MR & $0.22 \pm 0.08$ & $--\cdot$ & -.. & $1.53 \pm 0.11$ & -- & $0.30 \pm 0.05$ \\
\hline Regal & MR & $0.20 \pm 0.08$ & --- & $0.64 \pm 0.11$ & $1.38 \pm 0.34$ & -- & -.. \\
\hline
\end{tabular}

${ }^{2}$ Relative to the internal standard, hexaconsanol silyl ether.

${ }^{y}$ Molecular weight based on GC/MS analysis of silylated extracts.

${ }^{x}$ Calculated assuming chromatographic response of boehmeryl acetate; average of three five-root replications.

" $\mathrm{S}=$ weevil-susceptible line, $\mathrm{MR}=$ lines displaying moderate levels of resistance to the sweetpotato weevil.

"Not detectable.

sponsible for cultivar differences and oviposition stimulation reside in the periderm of the storage root.

Biologically active chemicals synthesized by the host plant can potentially modulate any stage of the weevil's interaction with the host, from host-finding through feeding, oviposition, and larval development. Among the various possible biological responses of the weevil, feeding and oviposition may be largely controlled by compounds found on the sulfate (Stadler, 1986). Present evidence indicates that boehmeryl acetate (peak 5) is biologically an important component through its action as an ovipositional stimulant to the female weevil (Wilson et al., 1989). Whether this compound acts alone or in concert with other components is not currently known. It is highly probable, however, that other compounds are also important, since both feeding and oviposition are seldom explained by a single chemical (Stadler, 1986). Further elucidation of chemical components that modulate weevil behavior and their use as selection criteria can potentially enhance the rate at which sweetpotato breeders can increase resistance to the weevil in future cultivars.

\section{Literature Cited}

Arrendale, R.F., R.H. Severson, and O.T. Chortyk. 1984. Open split interface for capillary gas chromatograph/mass spectrometry. Anal. Chem. 56:1533-1537.

Cockerham, K.L., O.T. Deen, M.B. Christian, and L.D. Newsome. 1954. The biology of the sweet potato weevil. Louisiana. Agr. Expt. Sta. Bul. 483:1.

Espelie, K.E., N.Z. Sadek, and R.E. Kolattukudy. 1980. Composition of suberin-associated waxes from the subterranean storage organs of seven plants. (Parsnip, carrot, rutabaga, turnip, red beet, sweet potato and potato). Planta 148:468-476.

Hedin, P.A. 1986. Developing research trends in the chemistry of plant resistance to pests, p. 1-4. In: M.B. Green and P.A. Hedin (eds.). Natural resistance of plants to pest. ACS Symp. Ser. 296, Washington, D.C.

Jones, A., P.D. Dukes, J.H. Schalk, M.G. Hamilton, M.A. Mullen, R.A. Baumgardner, D.R. Paterson, and T.E. Boswell. 1983. 'Resisto' sweet potato. HortScience 18:251-252.

Jones, A., P.D. Dukes, J.H. Schalk, M.G. Hamilton, M.A. Mullen, R.A. Baumgardner, D.R. Paterson, T.E. Boswell. 1985. 'Regal' sweet potato. HortScience 20:781-782.

Kays, S.J. and R.J. Horvat. 1983. Insect resistance and flavor chem- istry: Integration into future breeding programs. p. 97-106. In: F.W. Martin (ed.). Breeding new sweet potatoes for the tropics. Amer. Soc. Hort. Sci. Trop. Reg. 27(B).

Morrison, R.I. and W. Bick. 1967. The wax fraction of some soils: Separation and determination of some components. J. Sci. Food Agr. 18:351--355.

Mullen, M.A. 1984. Biology of the sweetpotato weevil, Cylas formicarius elegantulus (Summers), and selection for resistance in the sweet potato, Ipomoea batatas (L.) Lam., p. 17-29. In: M.A. Mullen and K.A. Sorensen (eds.). Proc. Sweetpotato Weevil workshop Southeastern Branch Entomol. Soc. Amer. Meetings, New Orleans, La.

Mullen, M.A., A. Jones, R.T. Abrogast, D.R. Paterson, and T.E. Boswell. 1981. Resistance of sweet potato lines to infestation of the sweet potato weevil, Cylas formicarius elegantulus (Summers). HortScience 16:539-540.

Mullen, M.A., A. Jones, D.R. Paterson, and T.E. Boswell. 1985. Resistance in sweet potatoes to the sweet potato weevil, Cylas formicarius elegantulus (Summers). J. Entomol. Sci. 20:345-350.

Nottingham, S.F., D.D. Wilson, R.F. Severson, and S.J. Kays. 1987. Feeding and oviposition preferences of the sweet potato weevil, $C y$ las formicarius elegantulus, on the outer periderm and exposed inner core of storage roots of selected sweet potato cultivars. Entomol. Expt. Appl. 45:271-275.

Severson, R.F., R.F. Arrendale, O.T. Chortyk, A.W. Johnson, D.M. Jackson, G.R. Gwynn, J.F. Chaplin, and M.G. Stephenson. 1984. Quantitation of the major cuticular components from green leaf of different tobacco types. J. Agr. Food Chem. 32:566-570.

Son, K.-C., R.F. Severson, R.F. Arrendale, and S.J. Kays. 1989. Isolation and characterization of a pentacyclic triterpene ovipositional stimulant from Ipomoea batatas Lam. J. Agr. Food Chem. 38:134-137.

Stadler, E. 1986. Oviposition and feeding stimuli in leaf surface waxes, p. 105-122. In: B.E. Juniper and T.R.E. Southwood (eds.). Insects and the plant surface. Edward Arnold, Baltimore.

Wilson, D.D., R.F. Severson, K.-C. Son, and S.J. Kays. 1988. Oviposition stimulant in sweet potato periderm for the sweet potato weevil, Cylas formicarius elegantulus (Summers). Environ. Entomol. 17:691-693.

Wilson, D.D., K.-C. Son, S.F. Nottingham, R.F. Severson, and S.J. Kays. 1989. Characterization of an oviposition stimulant from the surface of sweet potato Ipomoea batatas storage roots for the sweet potato weevil, Cylas formicarius elegantulus. Entomol. Expt. Appl. 51:71-75. 